\title{
Exploring the meaning of home for family caregivers of people with dementia
}

Dia Soilemezi, Amy Drahota, John Crossland, Rebecca Stores, Alan Costall

\begin{abstract}
The home remains the preferred site for ageing and care provision, yet its role and meaning for caregivers remains under-studied. Thirteen co-resident family caregivers of people with dementia were interviewed about the personal meaning of their home environment. Interviews were recorded, transcribed and analysed using thematic analysis. The findings revealed that 'home is everything' for caregivers and included two major themes, each with two sub-themes: 1 . The different meanings of home: 1.1 home as a secure haven, and 1.2 home looks like a hospital, feels like as a prison. 2 . Perceived impact of home: to move or not to move? 2.1 need for relocation, and 2.2 staying in place but redefine the home environment. The findings provide insights into the meaning of home and ways it may change, and identify areas for further exploration and also practical support for coresident caregivers in their own homes.
\end{abstract}

\section{Keywords}

Home environment; family caregivers; ageing in place; dementia; meaning of home; qualitative study 


\section{Introduction}

Dementia is a public health priority affecting millions of people globally (Prince et al., 2015). Although of great benefit for patients and society, caring for a person with dementia can often be at considerable cost for the caregiver, affecting their physical and mental health, social interactions, finances, and quality of life (WHO, 2012). In particular, cohabiting caregivers are likely to experience depression and anxiety (Mahoney, Regan, Katona, \& Livingston, 2005), and feel stuck in their role (Landmark, Aasgaard, \& Fagerstrom, 2013), although they are considered to provide protection against admission to a care facility (Banerjee et al., 2003). Unlike formal or other family caregivers, co-resident caregivers cannot 'go home' at the end of the shift or end of the day (Mahoney et al., 2005).

Given the increasing rise of dementia and community care policies that emphasise the need to support people at home and ageing in place, studies have investigated the role of the home environment in health and wellbeing (Vasunilashorn, Steinman, Liebig, \& Pynoos, 2012). Home is an important and meaningful place for people of all ages and cultures, especially for older people, as it is the primary setting for ageing. Home holds multiple psychological meanings and values (Moore, 2000), promoting feelings of safety, security, control, freedom, and providing shelter, refuge and retreat for the self (Rubinstein, 1989; for a literature review see Després, 1991 and Mallett, 2004), linking our past experiences, preserving and providing continuity of our self-identity (Chaudhury \& Rowles, 2005; Tanner, Tilse, \& de Jonge, 2008). Research has highlighted the importance of cultural, social and political norms in conceptualising the notion of home (Moore, 2000; Seo, 2010) and its potential effect on ontological security, health and wellbeing (Shaw, 2004). Home becomes the centre of life for older people due to increased time spent indoors, established social links and also due to health and mobility difficulties (H. Chaudhury \& Rowles, 2005; DahlinIvanoff, Haak, Fänge, \& Iwarsson, 2007; Haak, Ivanoff, Fänge, Sixsmith, \& Iwarsson, 2007; 
Oswald \& Wahl, 2004; Saunders, 1989; Swenson, 2010). Older people are attached to their homes and more committed to remaining in place. As Saunders (1989; p.183) has put it, "for the young, the home is a point on housing career trajectory; for the old, it is the end point of such a trajectory”. Especially for family caregivers of people with dementia who spend a lot of time indoors, the interior home space is significant as their 'primary restorative context' (Betrabet Gulwadi, 2009).

A number of researchers have developed approaches to the evolving meaning of home and its multi-dimensional nature (Oswald \& Wahl, 2004; Saunders, 1989; Sixsmith, 1986; Somerville, 1992), mostly including two principal dimensions of the meanings of home: (a) a socio-cognitive- psychological dimension, associated with family, happiness, identity and privacy, and (b) a physical/spatial dimension, associated with shelter, security, comfort and relaxation. The meaningful relationship that people form between the social, physical, psychological, and personal dimensions of their 'house' to create a 'home' develops and intensifies throughout the life span (Gillsjö, Schwartz-Barcott, \& von Post, 2011; Swenson, 2010). It is closely associated with life stability, healthy ageing, and quality of life (Boström, Bravell, Lundgren, \& Björklund, 2013). It also enables older people to feel safe (Petersson, Lilja, \& Borell, 2012), and results in the 'feeling at home'; as a 'perfect' state of being (Zingmark et al., 1995). Disruptions of this feeling at home, most importantly, through relocation, may result in changes in wellbeing (Chaudhury \& Rowles, 2005).

Home is an organic and transitional space, whereby its meaning(s) change(s) continuously. Home may acquire new personal significance or ambivalence to fit the psychological and functional needs in different life stages and circumstances in time and space (Angus, Kontos, Dyck, McKeever, \& Poland, 2005; Oswald \& Wahl, 2005; Rubinstein, 1990; Saunders, 1989). In long-term home care, 'institutionalisation' of home (Milligan, 2003), especially when room functions have changed (e.g. the living room 
becoming a bedroom), home may cease to be a place of safety, control, sanctuary and privacy and may become a place of disability, intrusion and insecurity. The personal and homely atmosphere can thus change instead into a medicalised space (Tamm, 1999; Teeland, 1998), disrupting autonomy, identity and wellbeing, and compromising the value and meaning of home for both the individual and the family (Hawkins \& Stewart, 2002), sometimes even upsetting familiar rhythms at home (Betrabet Gulwadi, 2013). Inhabitants may experience a 'dis-location' from home as it becomes a work place, like a hospital ward, when formal care is needed daily (Milligan, 2003) and increasingly loses its privacy, which is an essential aspect of the meaning of home (Teeland, 1998).

Yet, modifications can strengthen the meaning of home as a place of security, control and comfort for older people, reinforcing their self-efficacy, restoring the homeostasis at home, and reducing the assistance required from their family caregivers (Tanner et al., 2008). Although the significance of the physical domestic environment is unquestionable (Gitlin, Liebman, \& Winter, 2003; Shaw, 2004; Soilemezi, Drahota, Crossland, \& Stores, 2017), its meaning and role remain empirically under-studied.

Aminzadeh and colleagues (2010) suggested that home adaptations or restrictions result in disorder or intrusion, and change the emotional meaning of home for people with dementia. To our knowledge, since Rubinstein's (1990) research in the USA, which examined the meaning of home for both people with dementia and their family caregivers, there have been no primary studies exploring the meaning of home for caregivers of people with dementia and whether it has changed. The present study aims to address this gap by answering the following questions:

1. What does home mean to caregivers of people with dementia and how has it changed since they became caregivers? 
2. What elements in their home environment are important and/or challenging for caregivers and why?

\section{Design and Methods}

This study is a part of a cross-sectional qualitative study that explored caregivers' perspectives on both subjective (personal, social, psychological, existential) and objective (physical, structural, sensory and functional) aspects of housing. The present paper reports on the first aspect. In general, the study was informed by the person-environment fit model (ecological theory of ageing) developed by Lawton \& Nahemow in the 1970s, which is the leading framework examining transactions between the older person and the environment (Gitlin, 2003; Kahana, Lovegreen, Kahana, \& Kahana, 2003; Lawton, 1997). According to this model, environmental demands can often be the primary cause of both negative behaviours and poor outcomes for both the person with dementia and caregivers (Sadowsky \& Galvin, 2012; van Hoof \& Kort, 2009). This model proposes that the environment (not the person) should be modified to fit the person's competences, and it has been widely used in research promoting environmental quality.

Phenomenological sedentary and walking interviews were used to explore the caregivers' lived experience. Walking interviews, also known as "go-along” interviews, are traditionally used in geographical and urban planning, and are a novel approach in dementia research. In comparison with the traditional (static) interviews, walking interviews encourage participants' ongoing contacts with their surrounding environment and elicit detailed, context-sensitive perceptions of spatial practices and their impact (Carpiano, 2009; Evans \& Jones, 2011; Van Cauwenberg et al., 2012). Walking interviews combine field observation and interviewing and allow the researcher to observe the participants' interactions directly in their natural setting (Carpiano, 2009). The environment acts as a prompt and offers stimuli for further discussion and questioning. According to Keady et al. (2012) walking with the 
participants "can illuminate the practical and subjective experience of moving around a familiar zone of experience and the biographical connections it holds" (p.160).

Initially a purposive and convenience sampling approach was used, followed by snowball sampling and word-of-mouth referrals. Recruitment was carried out using community gatekeepers (Alzheimer's Society, Care UK, and local community groups). Participants were unknown to the researcher prior to study commencement, but the majority of caregivers were known to services. Because this study was aiming to gather different perspectives, diversity in terms of types of accommodation, gender, age, years of caring, and location was desirable. Recruitment occurred between January and June 2013.

After a pilot phase (December 2012) with two caregivers, eleven more caregivers were interviewed $(n=13)$. The study included all participants who had contacted the researcher to express an interest in participating, apart from one due to physical illness. Those eligible for inclusion were family co-habiting caregivers, living in Portsmouth and the surrounding area in the county of Hampshire (UK), who also had the mental capacity to consent at the time of the study. All participants were interviewed once. Each interview began by gathering basic demographic data and participants' general views about their home environment, before walking around each room to discuss the environment in more depth. Interviews were digitally recorded and transcribed verbatim. The recorded interviews lasted 39 - 79 minutes (average 60 minutes). Participants were informed of confidentiality, anonymity issues and how the data would be managed. They were all allocated a number and names were removed from all written reports.

The Faculty of Science Ethics Committee, Portsmouth City Council, members of the Engage (our public involvement panel) and informal caregivers reviewed the recruitment leaflets before distribution. Potential participants received a study leaflet from their group coordinator within the relevant organisation explaining the study and inviting them to take 
part. Interested caregivers posted back a reply slip in a pre-paid envelope, indicating their availability. A mutually convenient time was arranged to visit caregivers in their residence. A few days before the interview, participants received a provisional interview schedule to minimise anxiety and allow time for reflexivity and preparation. Previous environmental studies influenced the development of the interview schedule to capture challenges and tensions at home and understand participants' experiences and interactions with their environment. Elements of the environment (e.g. photographs, equipment) were used as prompts, where appropriate, to understand how caregivers conceptualised and manipulated their home environment. On the day of the interview, the caregivers were contacted once again to confirm their availability or to reschedule if necessary. Participants were encouraged to be seen alone where possible. In three interviews, however, the person with dementia was present throughout and in one arrived mid-way through the interview, but could not participate, as they had not given informed consent. A voucher was given to all participants as a 'thank you' gesture at the end of the study.

The data were analysed using thematic analysis in six phases (Braun \& Clarke, 2006), with the aid of QSR International's NVivo 10 Software. All transcripts and notes were repeatedly read and preliminary interesting points were written. Each line of each transcript was then read and coded to capture an interesting feature related to the research questions. Following that, an extensive number of initial codes were created that were grouped together to reveal a similar interesting point. These grouped codes (initial themes) were carefully checked back against each transcript to review the meaning and redefine it if necessary. The revised themes were then checked against all transcripts to ensure they relate back to the original text in a systematic and clear way. The themes were developed by first author (DS) and were later presented and discussed with all co-authors, who discussed their relevance and read several quotations that supported each theme. The final themes were then formed and 
written, making final refinements to keep the participants' story as clear and vivid as possible. Original text extracts were chosen across participants to emphasise an important point and enrich the reported story. The first author (DS) designed the study and materials, conducted all interviews, data coding, analysis and write-up. She had previous research experience of interviewing participants and also clinical experience of supporting people with dementia.

Although the person-environment theory provided the general orientation, the placeidentity theory developed by Proshansky, Fabian, \& Kaminoff (1983) and the meaning of home theory developed by Somerville (1992) have informed more specifically the data analysis by raising awareness, refining of constructs, and framing the final themes. Placeidentity theory links one's identity with the space and place ('place-belongingness'). Placebelongingness is a personal cognitive construction that is modified over the course of lifetime and evolves in response to continuous transactions with the physical and social world, providing symbolic and affective meanings of the environment, protecting self-identity and promoting wellbeing. According to this theory, people experience their physical settings by having good/bad feelings and attitudes about those settings, which can change over time. Places (one's home, neighbourhood, etc) may change radically and so will one's feelings and perceptions about them. Although it is a personal construction, other people's thoughts about physical settings also play a role in shaping one's place -identity. Place identity has several functions: it provides an environmental past and compares familiar with unfamiliar day-today settings, it provides meanings to places to understand roles, behaviours and required functions, it helps in dealing with changes in the environment and dealing with others in our space, and protects against anxiety and other dangers (Proshansky et al., 1983).

According to Somerville (1992) home is constructed through the interplay between three complementary dimensions (physical, social-cultural, and personal-psychological). 
According to this theory, home is a multidimensional concept, with at least six or seven underlying concepts: shelter, hearth, heart, privacy, roots, abode, paradise. Home is a socially constructed concept incorporating both elements of ideality and reality (Somerville, 1992)

\section{Results}

All 13 participants ( 9 female, 4 male) were White British and living with a person with dementia. One caregiver (CA02) was an adult daughter, who had to give up work since moving in with her mother; the rest were retired spouses (Table 1). They had been caregivers for an average of 3.5 years (ranging from 1 to 6 years). Participants lived in different types of accommodation that varied in type, layout and size, ranging from a one-bedroom apartment to four bedroom houses. Caregivers had been living in their current residence for an average of 18 years (ranging from <1 to 45 years). Six caregivers had lived long-term in the same property; six caregivers had moved and one couple (CA07) was looking to move to a more suitable accommodation. Eleven participants were providing assistance with activities of daily living (e.g. dressing, washing, cooking) as well as instrumental activities of daily living (e.g. medication, finances, shopping). Five female and one male caregiver were also assisting with toileting needs. Two caregivers reported that they were not providing personal care, but had taken over all other household responsibilities. Five caregivers mentioned receiving regular support from other family members (mostly from their sons and daughters) and occasionally from the neighbours. Two participants (CA06, CA10) were paying for professional caregivers to come in regularly and another caregiver (CA01) had a sitter for four hours weekly, which was provided for free from the local council. Two caregivers (CA07, CA10) were offered free sitting and respite, but had declined due to previous negative experiences. Ten participants were attending local support groups when possible. 
The experiences of the cohabiting caregivers are described according to two main themes: 1 . the different meanings of home and 2. the perceived impact of the home environment: to move or not to move? (Table 2).

3.1 The different meanings of home. All interviewees made clear that their home was a place with significant personal meanings and described it as a very important place for them and their relative: "home is everything" (CA03, female, 62 years old, living in a house for 6 years and caring for 6 years). Most of them expressed positive and gratifying views of their home that highlighted its benefits (subtheme 1.1). However, just as their roles changed, so did the whole home experience and home had become compromised in some shape or form (subtheme 1.2).

3.1.1 Home as a secure haven. In general, home was strongly associated with security, safety, familiarity, comfort, and happiness. It was also considered the hub of the caregivers' lives, their nest and a place they spent the majority of their time since starting to care for a person with dementia. All but one caregiver felt safe to be at home and were also reassured when their relative was at home, "I always feel safe when I'm in my house... because it's easier to care for my husband here... I worry about him in other places" (CA06, female, 74 years old, living in a house for 45 years and caring for 1 year). It is precisely that sense of safety that allowed them the freedom of action. As such, home was perceived as a place of retreat and a place of control, where they can discard the social persona and be themselves. "It's for both of us, it's, ah, release yourself, you can do what you want in your home" (CA08, male, 64 years old, living in an apartment for 16 years and caring for 3 years). Seven caregivers considered their home to reflect their personality and link strongly to their identity. Home was full of memories, mementos reflecting their life journey, their family 
formation, their personal interests, which infused strong positive feelings and emotional support.

You got all your memories in your home as well, haven't you? ... I think that's home; somewhere that I can nest that has my personality showing ... And it's things like that [meaningful items] that give me the memories, the hints that take me straight back, even when really tired, to a good time in the past or the hope for a good time in the future... I think it's about that, having the identity of me before caring, the memories of the good times before just to remind you that it's not all bad (CA02, female, 51 years old, living in a bungalow for 6 months and caring for six years).

Other caregivers talked about the importance of having meaningful objects displayed around their home to provide them with a sense of security, self-identity and remind them of happy family moments:

I guess if there was a fire I'd have to grab that [family] photo... so that's really important, makes me feel like I'm still part of a family even if I don't see them very much (CA05, female, 67 years old, living in a house for 23 years and caring for 3 years).

3.1.2 Home looks like a hospital, feels like a prison. All caregivers talked about intrusions into their daily routine and physical surroundings of their home, mainly modifications and use of equipment. Although perceived as very helpful to safeguard against possible risks, equipment had changed the ambience, especially in the bedroom and living room. For those caregivers, home ceased to be a place of comfort and self-expression and 
turned into a place of stress and inconvenience, resembling a hospital. Two caregivers commented on unpleasant features (smells and the presence of care equipment) and strategies used to maintain a sense of normality and a homely atmosphere.

There's been a lot of disabled equipment coming in, which has taken up space, like a commode, toilet aids, bed aids, wheel chair so your home has taken-been like a hospital sometimes; I have to hide the commodes because it's not very nice when people come in (CA10, female, 69 years old, living in a house for 15 years and caring for 5 years).

Care at home also led to compromises in space, in aesthetics, and/or in sensory environment: "My wife will prefer not [to have music on], she loves it quiet, so I used to put the radio on every morning but we don't now" (CA11, male, 75 years old, living in an apartment for 8 months and caring for 3 years). Eight caregivers had to decide whether to keep, hide or replace appliances (e.g. sacrificing the bath for a walk-in shower) and furniture, "we don't have a coffee table in the middle of the room, which I would love to have because of, you know, problems" (CA10, female, 69 years old, living in a house for 15 years and caring for 5 years). Additionally, nine caregivers reported feeling trapped, and isolated, "I am very tied to the flat, you know. I can't go out, no, I don't go out at all; only once a week" (CA01, female, 81 years old, living in an apartment for 1 year and caring for 2 years). The home ceased to be a place of freedom and gradually became a locus of confinement, even a prison.

I could say [home is] like a prison now really... because you are trapped in here a lot... [before home was] somewhere to relax I think and feel free and 
that, but home... you are all trapped in now (CA03, female, 62 years old, living in a house for 6 years and caring for 6 years).

Similarly, these caregivers had to restrict or change their social life and hobbies (mainly to indoor) to remain at home looking after their relative. The majority of caregivers had support from friends and family; five reported that family members avoided them or lived too far to provide support. The home as a place of family gatherings and social life was gradually shrinking: "We don't sort of do things outside and we, we don't have so many people coming in anymore either ... Yeah, things have changed a lot" (CA13, female, 64 years old, living in a house for 1 year and caring for 5 years).

3.2 Perceived impact of home: to move or not to move? Inevitably, all of the caregivers said that they were facing serious decisions on how to deal effectively with their home environment. In six cases caregivers had decided to relocate; others remained in place but their home had become increasingly hard to maintain due to both the additional responsibilities and inconvenience caused by the added equipment and adaptations. Six caregivers, who considered their domestic setting unhelpful, had moved with their relative to a new property (subtheme 2.1). Others thought that the environment was not something that they would change as they were set in the way it was for years. Four participants acknowledged the great impact of their home environment on them: "If you are here the whole time, 24 hours the day, the environment is more important" (CA02, female, 51 years old, living in a bungalow for 6 months and caring for 6 years). Nevertheless, all caregivers expressed a need to redefine their home space (subtheme 2.2) due to two main reasons: lack of safety and/or lack of comfort (physical or emotional). Whether they remained in place and adapted their existing home to add comfort, or whether they relocated to a new home to add 
safety, the role of the home environment was seen as preventing risks, encouraging autonomy and reducing the impact of supporting someone with dementia.

3.2.1 Need for relocation. The caregivers mentioned the following as reasons for constantly worrying and also for possible relocation: fear of falling, fear of being injured, incontinence, wandering behaviour, physical weakness and unfit environment (e.g. stairs). Six caregivers who moved to a new home with fewer hazards reported that this transition was necessary to regain control, prevent institutional placement and ease the impact of supporting their relatives. The caregivers' experiences ranged from moving back to the UK (CA11), moving to a different town to be closer to family (CA01), or moving a few blocks away from their old neighbourhood (CA13). Caregivers mentioned two different strategies to assist them settling in: maintaining the familiarity and detachment. Two caregivers, who employed the first strategy, brought along familiar objects and furniture, positioning them in familiar places and layout to simulate the routes from their older residence to make the transition smoother for the person with dementia and recreate the meaning of home for the caregiver.

The most important thing was to get the furniture around, particularly the books and the bookcases, and get the pictures up in the wall, which were familiar and she didn't even realise she had moved... we actually had the bed where that radiator is here because coming out in the night, turn right and left the bathroom, is the exactly same path she had in the flat (CA02, female, 51 years old, living in a bungalow for 6 months and caring for 6 years).

On the other hand, in order to detach themselves from the old house, two caregivers decided to leave their old possessions and previously cherished objects and bought new furniture and appliances, "it was all got rid of; it went" (CA01). This strategic decision can 
be explained by their need to start afresh and re-create a new, more suitable home based on their current needs and desires.

Similarly, the experience of residential relocation was described in both positive and negative terms. Two caregivers perceived it as an upheaval: "Really I have lost everything when I think about it" (CA01, female, 81 years old, living in an apartment for 1 year and caring for 2 years). Three caregivers did not mind the process and reported that both themselves and the person with dementia were happier in the new environment and relieved not to have to do any further modifications inside the property. Their new home had fewer hazards and that the transition made caregivers more relaxed, confident and 'in control' compared to the previous residence.

Since we've moved here I, I've been a lot more calm... I think it's helped me to be more calm and be able to, to care really... if we had had to stay in the flat, I think I probably would have had a breakdown (CA13, female, 64 years old, living in a house for 1 year and caring for 5 years).

Two caregivers who had moved to a more supportive accommodation felt safer, "peace of mind" (CA11, male, 75 years old, living in an apartment for 8 months and caring for 3 years) because they knew that there were alarms, cameras and support if needed. Opportunities for social interaction were regarded important in smoothing their transition and acquire new networks. Especially for one caregiver, the fact that other residents kept an eye out for his wife, enabled him to feel more relaxed, 'at home': "I'm not on the lookout all the time.... if she wanders off, she will be safe... it works, I can't say any more than that and that's a blessing" (CA11, male, 75 years old, living in an apartment for 8 months and caring for 3 years). 
3.2.2 Staying in place but redefine the home environment. Most of the caregivers were aware of possible changes in their relative's functioning and all had already implemented environmental solutions, either as a result of professionals' recommendation or their own improvisations. All caregivers strongly opposed the idea of moving their relative to another care setting. Home was the preferred place to care for their relatives until the end: "I think she can get more emotional support being in her own home than in a care home where there is lots of noise, lots going on" (CA02, female, 51 years old, living in a bungalow for 6 months and caring for 6 years).

Seven caregivers admitted struggling with aspects of their home (e.g. stairs), but they clearly downplayed the problems (apart from one caregiver) because leaving their home was unthinkable. The meaningfulness of their home was so strong that it compensated for their home's physical deficits: "I can't imagine living anywhere else; we've adapted my husband's illness to fit in the house really or it should be the other way round [laughs]" (CA10, female, 69 years old, living in a house for 15 years and caring for 3 years).

Caregivers who had remained in the same place discussed their need to refresh and redefine their environment, possibly stemming from their need to be more comfortable at home "because I thought it would brighten me up" (CA06, female, 74 years old, living in a house for 45 years and caring for 1 year). The scale of changes varied, depending largely on personal circumstances. Five caregivers reported that the process of refreshing their home was therapeutic and empowering: "It [decorating] helps to take my mind off things... it's the one thing I can control" (CA02, female, 51 years old, living in a bungalow for 6 months and caring for 6 years).

In redefining space, six caregivers relocated to another bedroom, permanently or temporarily, to cope and get much needed sleep. Eight caregivers created a hide-away, an 'escape room', where they created a personalised environment, the aesthetics and use of 
which they could control. It was a room, physically and emotionally, just for the caregiver, not associated with caring, disability, or illness. It was regarded as a necessary strategy to restore normality and, most importantly, maintain their identity, "I feel like a caregiver now and not a wife" (CA05, female, 67 years old, living in a house for 23 years and caring for 3 years). Escape spaces were seen as a special symbol of their self-identity:.

I am going to make a couple of rooms here very much my own and the room upstairs is going to be quite important... I hear young mothers talking about that, they start feeling that they are only someone's mum and they are not an individual anymore and I think it's the same thing, I think you need space... in the bad days, you need them [separate rooms] so you can comfort yourself (CA02, female, 51 years old, living in a bungalow for 6 months and caring for 6 years).

\section{Discussion}

This is the first study to provide rich empirical evidence about the meaning of home and how it changes over time for family caregivers living with a person with dementia. Caregivers conceptualised their home as a source of security, happiness, haven, familiarity, belonging, privacy, freedom, identity, shelter, retreat, and comfort, and this is consistent with earlier empirical studies that utilised different types of participants, i.e. family caregivers to disabled people, older adults, students (Betrabet Gulwadi, 2009; Boström et al., 2013; Gillsjö

et al., 2011; Milligan, 2003; Petersson et al., 2012; Saunders, 1989; Sixsmith, 1986). Our findings showed that the meaning of home for co-resident caregivers of people with dementia is likely to change or be disrupted due to a number of significant compromises within their 
physical space. Previous research suggests that this is also the case for the people with dementia themselves (Aminzadeh et al., 2010; De Witt, Ploeg, \& Black, 2009). Such negative disruption was notable for caregivers who transitioned to a new residence and those who remained in place. Although caregivers acknowledged the considerable benefits of home adaptations, in some cases these adaptations had significantly changed the meaning of home from a place of emotional and physical comfort (haven) into a hospitalised space. In removing physical barriers for the person with dementia, symbolic barriers can be created for caregivers that restrict or alter the meaning and experience of their own home. For some caregivers, in the present study. their house was no longer a home and it had become an alienated space; this is in line with Golant's (2015) point that 'once-sacred boundaries between residential and care environments become blurred' (p. 9). This is an interesting finding given the current policy emphasis on supporting people to stay in their residencies for as long as possible.

Betrabet Gulwadi (2009) suggested that caring at home could disturb the home balance, autonomy, quality of life, and change the homely atmosphere (appearance, order, odours and décor) into a contested space with less pleasing aesthetic arrangements. This is especially evident when equipment is being introduced to support a specific human function but not to promote enjoyment (Betrabet Gulwadi, 2013; Hawkins \& Stewart, 2002; Milligan, 2003; Tamm, 1999). Caring equipment, often publicly visible, symbolises a change in status, loss, or dependency (Angus et al., 2005; Seo, 2010). Bentley and colleagues (1985) argued that visual appropriateness strongly affects the way people interpret, respond and give meaning(s) to a place and thus a home should look like a home and not like a hospital. The constant watchfulness, incontinence accidents, and secluded life adds to the feeling of home as an institution and not as a social space (de la Cuesta \& Sandelowski, 2005; Forbat, 2004). Additionally, home became a paradox, a source of continuous worry, a place of intrusion, 
isolation and for some caregivers even a place of unpleasant aesthetics and a prison. Portraying home as a prison has also been documented with very old people (Haak, Ivanoff, Fänge, Sixsmith, \& Iwarsson, 2007), family caregivers (Taşc1, Kartın, Ceyhan, Sungur, \& Göriş, 2012) and people with dementia (Aminzadeh et al., 2010; De Witt et al., 2009).

In dementia care, keeping the person with dementia at home represents consistency and familiarity, whereas changes (in routines and in living arrangements) may be perceived as a source of stress and threat for people with dementia and their family caregivers (Norman, Redfern, Briggs, \& Askham, 2004). However, in deciding where the best place to age is, there is no one-size-fits-all solution and sometimes changes are not bad as they may offer opportunities to improve the person-environment transactions (Lawton, 1990; Golant, 2015). Caregivers, who remain in place, may need to implement modifications for safety and independence, whereas relocation could be an alternative to adaptations (Heywood, 2005), facilitate family support (Wiles, Leibing, Guberman, Reeve, \& Allen, 2011), and provide relief through downsizing (Aminzadeh et al., 2010). In our study, some caregivers consciously sought new homes and attachments, 'conscious discontinuity', to mark a new stage in their life (Manzo, 2003). Caregivers who moved to a warden controlled flat also expressed a sense of security and safety for this decision, confirming previous studies (Bigonnesse, Beaulieu, \& Garon, 2014).

Consistent with the previous literature, meaningful personal items (e.g. photographs) were perceived as important transitional objects, to recreate home in the new settings as reminders of self-identity, and to provide a sense of continuity, belongingness, and wellbeing (Gillsjö et al., 2011; Shenk et al., 2004; Swenson, 2010). An equally helpful approach for some is a strategy of disengagement from their old accommodation and re-creating a sense of home with new objects (Seo, 2010). 
Our findings also suggest that caregivers may relocate to an appropriate living environment, when remaining in place was perceived as limiting the opportunities for safety, independence and wellbeing. Moving to a new residence gave the opportunity to have an ideal home, with no modifications. This is an important finding for two reasons. Firstly, it confirms previous studies that the environmental incongruities (e.g. a home environment not suitable to the residents' abilities and values) can compromise their wellbeing (Gitlin \& Corcoran, 2000) and provoke relocation (Kahana et al., 2003). Secondly, relocation was sometimes preferred to familiarity, which contradicts previous research suggesting that changes are a potential threat for people with dementia and their family caregivers (Norman et al., 2004). Although attachment to home and familiarity is important, it may limit people's choice of suitable housing (Wiles et al., 2011). Conversely, voluntary relocation may be more appropriate rather than staying in place, as some people oppose moving to nursing facilities and prefer moving to a more suitable residence.

Building on suggestions from previous studies that caregivers are in need of a clear division between caring and non-caring household space (Olsen, Hutchings, \& Ehrenkrantz, 1999), caregivers in our study also indicated a need to redefine their home environment and reported applying adaptation strategies via trial and error or even inadvertently. Caregivers with some degree of environmental competence created an escape room to have a 'home' within their house, a comfortable, relaxing and private space away from their caring tasks to support them in caring for longer. A place has to be comfortable and offer opportunities for control and privacy to become home (Calkins, 2001; Rubinstein, 1989), something that was clearly fading away for some of the participants in this study. Caregivers were mostly happy to put the home into the service of their relative, as long as they could keep a private space to restore privacy, maintain a sense of control and meaning(s) of home and preserve their identity beyond simply being a caregiver (Place-identity theory; see Prochansky et al, 1983). 
Experts in dementia-friendly dwellings (Gitlin, 2007; van Hoof \& Kort, 2009) recommend that caregivers set up a quiet and comfortable room or a private area in the bedroom for rest and this the present study adds empirical evidence to these recommendations. Heywood (2005) also emphasises the importance of 'away' private space as a human need for both the sake of caregivers and their relatives. This is a key finding considering that caregivers' stress is likely to be exacerbated by lack of privacy and space (Betrabet Gulwadi, 2009) and that self-image and relationships are threatened by home adaptations and the reduction of usable home space for other family members (Heywood, 2005).

Several authors have proposed explanations of the decision to relocate or remain in place. For example, Litwak \& Longino (1987) argued that migration is selective and there are typically three reasons of why people decide to relocate: (1) due to lifestyle choices and amenity reasons, (2) due to moderate disability and need for familial support, and (3) due to severe and chronic disability to an institutional setting (Bradley, 2011; Litwak \& Longino, 1987). According to the theory of supportive environments, a restorative environment needs to foster social support in order to promote the residents' wellbeing (Betrabet Gulwadi, 2009). The Place-identity theory (Proshansky et al., 1983) proposes that if the individual cannot change the physical environment or the behaviour of others, then they are likely to move to a more suitable setting. The same theory could explain why individuals choose not to relocate, by trying to bring harmony and hence change their own behaviour and develop coping techniques to minimise discrepancies. The creation of an escape room could be a result of caregivers' need to harmonise discrepancies between their environment and selfidentity. A personalised escape room is one such coping technique to rectify this. Influenced by the attention restoration theory, Betrabet Gulwadi (2009) also proposed two restorative strategies for caregivers to overcome emotional stress and the housebound feeling: (1) a temporary escape (physically and psychologically) within the home and (2) the need to 
restore their control over their familial environment. Both of these propositions are supported empirically in this study.

\section{Limitations}

Our data were derived from the perspectives of a small convenience sample of caregivers, and therefore limiting generalisation. Although the analysis required the analyst to remain very close to the data, it is a highly personal and subjective task, influenced by the researcher's educational background in health psychology and clinical experience in supporting people with dementia, and hence bias or loss of findings might have occurred. Furthermore, all participants had engaged in health and social services, implemented minor or major adaptations and therefore demonstrated some sense of environmental control, which might be a bias in the sample.

\section{Recommendations}

Health and social care professionals should consider housing adaptations while recognising the meaningfulness of living space to avoid unnecessary compromises. Considering only practical domains and physical barriers but ignoring the emotional experience of home would cause refusal of adaptations or wasted expenses (Heywood, 2005). The underuse of existing services by caregivers and resistance to risk measures (Cott \& Tierney, 2013) may be an indication of conflict of goals between what caregivers perceive as important and useful and what health and social care professionals suggest (Gitlin, Corcoran, \& Leinmiller-Eckhardt, 1995). As Heywood (2005) argued, the problem is not only that the meaning of home is an invisible factor, but also that informal caring itself can be invisible and isolating, which may be often overlooked. 
It is also crucial to acknowledge the advantages and limitations between staying in place and relocating. If relocation is desirable, professionals need to offer individualised support in planning the relocation, paying attention both to meaning and settling strategies (attachment to or discarding of items), on the personal meaning of home, the meaning of caregiving (Chung, 1997; Gitlin et al., 1995) and the meaning of risk (Cott \& Tierney, 2013), based jointly on the needs of the caregiver and the person with dementia (Olsen et al., 1999).

An escape room can be a valuable restorative strategy for caregivers to enhance inhome quality of life. It can be used as an indoor hobbies room, as a space for mental break and respite, or a place to withdraw when experiencing grief and loss of companionship. Respite breaks, although essential, are not always preferable or available when caregivers need it. An escape room can suit those caregivers who prefer indoors respite. This should be considered in the light of a Cochrane review indicating that respite care is not effective (Maayan, Soares-Weiser, \& Lee, 2014) and also previous research indicating that co-resident caregivers underuse formal services (Ory, Yee, Tennstedt, \& Schulz, 2000). Conversely, not all caregivers may find a respite break within their home helpful, but support should be offered from professionals to create one if needed.

It is also important to alert architects and home designers to the potential role of the home environment and consider opportunities for privacy and temporary escape (Betrabet Gulwadi, 2009; Heywood, 2005), while incorporating the unique personal meanings and social-cultural practices within the home space to enhance the feeling 'at home'. There is now a curious paradox that dementia care facilities are focusing on promoting homely environments, while people's own homes are increasingly being transformed into hospitallike spaces (de la Cuesta \& Sandelowski, 2005).

Further research should focus on home environments given the plurality of studies in institutionalised settings, and in particular, to explore the meaning of home across cultures, as 
home may symbolise different things to people in different cultures, elderly minorities and immigrants. Finally, in cases of relocation, research should consider the objective and subjective dimensions of the old and new home and the boundaries between them.

\section{Conclusion}

The home environment is very important for family caregivers of people with dementia and its meaning is likely to change. A home that was once a haven may be experienced as a sterile hospital scene and/or even a prison. Caregivers may face the dilemma of whether they need to relocate to a more supportive residence or redefine their existing living space into a more dementia-, but also caring-friendly environment. The creation of an escape room may be a cost-effective indoor respite strategy.

\section{Highlights}

- The experience of home is fragile resulting from interactions and negotiations among all household members and constantly readjusting to age, health and life events

- When caring for a person with dementia, a house may cease to be a home

- Home can be a memory enhancing device helping family caregivers to hold to their memories

- Caregivers need their own space to hold on to their identity and memories

- Inappropriate home environments may force relocation to enable safe and comfortable home life 


\section{References}

Aminzadeh, F., Dalziel, W. B., Molnar, F. J., \& Garcia, L. J. (2010). Meanings, functions, and experiences of living at home for individuals with dementia at the critical point of relocation. Journal of Gerontological Nursing, 36(6), 28-35.

http://doi.org/10.3928/00989134-20100303-02

Angus, J., Kontos, P., Dyck, I., McKeever, P., \& Poland, B. (2005). The personal significance of home: habitus and the experience of receiving long-term home care. Sociology of Health \& Illness, 27(2), 161-187. http://doi.org/10.1111/j.14679566.2005.00438.x

Banerjee, S., Murray, J., Foley, B., Atkins, L., Schneider, J., \& Mann, A. (2003). Predictors of institutionalisation in people with dementia. Journal of Neurology, Neurosurgery \& Psychiatry, 74(9), 1315-1316. http://doi.org/10.1136/jnnp.74.9.1315

Bentley, I., Alcock, A., Murrain, P., McGlynn, S., \& Smith, G. (1985). Responsive environments. A manual for designers. UK: Routledge.

Betrabet Gulwadi, G. (2009). Restorative home environments for family caregivers. Journal of Aging Studies, 23(3), 197-204. http://doi.org/10.1016/j.jaging.2007.11.005

Bigonnesse, C., Beaulieu, M., \& Garon, S. (2014). Meaning of home in later life as a concept to understand older adults' housing needs: Results from the 7 age-friendly cities pilot project in Québec. Journal of Housing For the Elderly, 28(4), 357-382. http://doi.org/10.1080/02763893.2014.930367

Boström, M., Bravell, M. E., Lundgren, D., \& Björklund, A. (2013). Promoting sense of security in old-age care. Health, 5(6), 56-63. http://doi.org/10.4236/health.2013.56A2009

Bradley, D. E. (2011). Litwak and Longino's developmental model of later-life migration: 
Evidence from the American Community Survey, 2005-2007. Journal of Applied Gerontology, 30(2), 141-158. http://doi.org/10.1177/0733464810386463

Braun, V., \& Clarke, V. (2006). Using thematic analysis in psychology. Qualitative Research in Psychology, 3(2), 77-101. http://doi.org/10.1191/1478088706qp063oa

Calkins, M. P. (2001). The physical and social environment of the person with Alzheimer's disease. Aging and Mental Health, 5(S1), 74-78. http://doi.org/10.1080/13607860120044837

Carpiano, R. M. (2009). Come take a walk with me: the "go-along" interview as a novel method for studying the implications of place for health and well-being. Health \& Place, 15(1), 263-72. http://doi.org/10.1016/j.healthplace.2008.05.003

Chaudhury, H., \& Rowles, G. D. (2005). Between the shores of recollection and imagination: self, aging, and home. International Perspectives. In G. D. Rowles \& H. Chaudhury (Eds.), Home and Identity in Late Life (pp. 3-18). New York: Springer Publishing Company, Inc.

Chung, J. C.-C. (1997). Focus on family care givers for individuals with dementia: Implications for occupational therapy practice. Occupational Therapy International, 4(1), 66-80. http://doi.org/10.1002/oti.48

Cott, C. A., \& Tierney, M. C. (2013). Acceptable and unacceptable risk: balancing everyday risk by family members of older cognitively impaired adults who live alone. Health Risk \& Society, 15(5, SI), 402-415. http://doi.org/10.1080/13698575.2013.801936

Dahlin-Ivanoff, S., Haak, M., Fänge, A., \& Iwarsson, S. (2007). The multiple meaning of home as experienced by very old Swedish people. Scandinavian Journal of Occupational Therapy, 14(1), 25-32. http://doi.org/10.1080/11038120601151714

de la Cuesta, C., \& Sandelowski, M. (2005). Tenerlos en la casa: The material world and craft of family caregiving for relatives with dementia. Journal of Transcultural Nursing, 
16(3), 218-225. http://doi.org/10.1177/1043659605274979

De Witt, L., Ploeg, J., \& Black, M. (2009). Living on the threshold: The spatial experience of living alone with dementia. Dementia, 8(2), 263-291. http://doi.org/10.1177/1471301209103273

Després, C. (1991). The meaning of home: Literature review and directions for future research and theoretical development. The Journal of Architectural and Planning Research, 8(2), 96-115. Retrieved from http://www.jstor.org/stable/43029026

Evans, J., \& Jones, P. (2011). The walking interview: Methodology, mobility and place. Applied Geography, 31(2), 849-858. http://doi.org/10.1016/j.apgeog.2010.09.005

Forbat, L. (2004). Listening to carers talking about the subjects of continence and toileting. Nursing Times, 100(2), 46-49. Retrieved from http://search.ebscohost.com/login.aspx?direct=true $\& d b=$ cmedm $\& A N=14768154 \&$ site $=$ ehost-live

Gillsjö, C., Schwartz-Barcott, D., \& von Post, I. (2011). Home: the place the older adult can not imagine living without. BMC Geriatrics, 11(1), 10. http://doi.org/10.1186/14712318-11-10

Gitlin, L. N. (2003). Conducting research on home environments: lessons learned and new directions. The Gerontologist, 43(5), 628-37. http://doi.org/10.1093/geront/43.5.628

Gitlin, L. N. (2007). Guidelines for environmental adaptations and safety at home. Alzheimer's Care Today, 8(3), 278-281. Retrieved from http://search.ebscohost.com/login.aspx?direct=true \&db=cin20\&AN=2010202920\&site= ehost-live

Gitlin, L. N., \& Corcoran, M. (2000). Making homes safer: Environmental adaptations for people with dementia. Alzheimer's Care Quarterly, 1(1), 50-58. Retrieved from http://journals.lww.com/actjournalonline/Abstract/2000/01010/Making_Homes_Safer__ 
Environmental_Adaptations_for.9.aspx

Gitlin, L. N., Corcoran, M., \& Leinmiller-Eckhardt, S. (1995). Understanding the family perspective: An ethnographic framework for providing occupational therapy in the home. The American Journal of Occupational Therapy, 49(8), 802-809. http://doi.org/10.5014/ajot.49.8.802

Gitlin, L. N., Liebman, J. M., \& Winter, L. (2003). Are environmental interventions effective in the management of Alzheimer's disease and related disorders?: A synthesis of the evidence. Alzheimer's Care Quarterly, 4(2), 85-107. Retrieved from http://journals.lww.com/actjournalonline/Abstract/2003/04000/Are_Environmental_Inte rventions_Effective_in_the.3.aspx

Golant, S. M. (2015). Aging in the right place. Baltimore, MD: Health Professions Press. Gulwadi Betrabet, G. (2013). Establishing continuity of self-memory boxes in dementia facilities for older adults: Their use and usefulness. Journal of Housing for the Elderly, 27(1/2), 105-119. http://doi.org/10.1080/02763893.2012.754817

Haak, M., Ivanoff, S. D., Fänge, A., Sixsmith, J., \& Iwarsson, S. (2007). Home as the locus and origin for participation: experiences among very old Swedish people. OTJR: Occupation, Participation and Health, 27(3), 95-103. http://doi.org/10.1177/153944920702700303

Hawkins, R., \& Stewart, S. (2002). Changing rooms: the impact of adaptations on the meaning of home for a disabled person and the role of occupational therapists in the process. British Journal of Occupational Therapy, 65(2), 81-87. http://doi.org/10.1177/030802260206500206

Heywood, F. (2005). Adaptation: Altering the house to restore the home. Housing Studies, 20(4), 531-547. http://doi.org/10.1080/02673030500114409

Kahana, E., Lovegreen, L., Kahana, B., \& Kahana, M. (2003). Person, environment, and 
person-environment fit as influences on residential satisafaction of elders. Environment and Behavior, 35(3), 434-453. http://doi.org/10.1177/0013916503035003007

Keady, J., Campbell, S., Barnes, H., Ward, R., Li, X., Swarbrick, C., ... Elvish, R. (2012). Neighbourhoods and dementia in the health and social care context: a realist review of the literature and implications for UK policy development. Reviews in Clinical Gerontology, 22(2), 150-163. http://doi.org/10.1017/S0959259811000268

Landmark, B. T., Aasgaard, H. S., \& Fagerstrom, L. (2013). “To be stuck in it--I can't just leave": A qualitative study of relatives' experiences of dementia suffers living at home and need for support. Home Health Care Management \& Practice, 25(5), 217-223. http://doi.org/10.1177/1084822313487984

Lawton, M. P. (1990). Residential environment and self-directedness among older people. American Psychologist, 45(5), 638-640. http://doi.org/10.1037/0003-066X.45.5.638

Lawton, M. P. (1997). An ecological theory of aging applied to elderly housing. Environments and Aging, 31(1), 8-10. Retrieved from http://www.jstor.org/stable/1424527

Litwak, E., \& Longino, C. F. (1987). Migration patterns among the elderly: A developmental perspective. The Gerontologist, 27(3), 266-272. http://doi.org/10.1093/geront/27.3.266

Maayan, N., Soares-Weiser, K., \& Lee, H. (2014). Respite care for people with dementia and their carers. Cochrane Database of Systematic Reviews (Online), (1), 1-49. http://doi.org/10.1002/14651858.CD004396.pub2

Mahoney, R., Regan, C., Katona, C., \& Livingston, G. (2005). Anxiety and depression in family caregivers of people with Alzheimer disease: The LASER-AD study. The American Journal of Geriatric Psychiatry, 13(9), 795-801. http://doi.org/10.1176/appi.ajgp.13.9.795

Mallett, S. (2004). Understanding home: a critical review of the literature. The Sociological 
Review, 52(1), 62-89. http://doi.org/10.1111/j.1467-954X.2004.00442.x

Manzo, L. C. (2003). Beyond house and haven: Toward a revisioning of emotional relationships with places. Journal of Environmental Psychology, 23(1), 47-61. http://doi.org/10.1016/S0272-4944(02)00074-9

Milligan, C. (2003). Location or dis-location? Towards a conceptualization of people and place in the care-giving experience. Social \& Cultural Geography, 4(4), 455-470. http://doi.org/10.1080/1464936032000137902

Moore, J. (2000). Placing home in context. Journal of Environmental Psychology, 20(3), 207-217. http://doi.org/http://dx.doi.org/10.1006/jevp.2000.0178

Norman, I., Redfern, S., Briggs, K., \& Askham, J. (2004). Perceptions and management of change by people with dementia and their carers living at home. Dementia, 3(1), 19-44. http://doi.org/10.1177/1471301204032614

Olsen, R. V, Hutchings, B. L., \& Ehrenkrantz, E. (1999). The physical design of the home as a caregiving support: an environment for persons with dementia. Care Management Journals, 1(2), 125-131. Retrieved from http://www.ncbi.nlm.nih.gov/pubmed/10644296

Ory, M. G., Yee, J. L., Tennstedt, S. L., \& Schulz, R. (2000). The extent and impact of dementia care: Unique challenges experienced by family caregivers. In R. Schulz (Ed.), Handbook on dementia caregiving: Evidence-based interventions for family caregivers. (pp. 1-32). NY: Springer.

Oswald, F., \& Wahl, H.-W. (2004). Housing and health in later life. Reviews on Environmental Health. Retrieved from http://www.psychologie.uniheidelberg.de/ae/apa/pdf/literatur/fo_housinghealth.pdf

Oswald, F., \& Wahl, H.-W. (2005). Dimensions of the meaning of home in later life. In G. D. Rowles \& H. Chaudhury (Eds.), Home and Identity in Late Life (pp. 21-45). NY: 
Springer.

Petersson, I., Lilja, M., \& Borell, L. (2012). To feel safe in everyday life at home - a study of older adults after home modifications. Ageing and Society, 32(5), 791-811. http://doi.org/http://dx.doi.org/10.1017/S0144686X11000614

Prince, M., Wimo, A., Guerchet, M., Gemma-Claire, A., Wu, Y.-T., \& Prina, M. (2015). World Alzheimer Report 2015: The Global Impact of Dementia - An analysis of prevalence, incidence, cost And trends. ADI: London.

Proshansky, H. M., Fabian, A. K., \& Kaminoff, R. (1983). Place-identity: Physical world socialization of the self. Journal of Environmental Psychology, 3(1), 57-83. http://doi.org/10.1016/S0272-4944(83)80021-8

Rubinstein, R. L. (1989). The home environments of older people: a description of the psychosocial processes linking person to place. Journal of Gerontology, 44(2), S45-53. http://doi.org/10.1093/geronj/44.2.S45

Rubinstein, R. L. (1990). Culture and disorder in the home care experience: the home as sickroom. In J. F. Gubrium \& A. Sankar (Eds.), The home care experience: Ethnography and policy. (pp. 37-57). Thousand Oaks, CA US: Sage Publications, Inc.

Sadowsky, C. H., \& Galvin, J. E. (2012). Guidelines for the management of cognitive and behavioral problems in dementia. Journal of the American Board of Family Medicine, 25(3), 350-66. http://doi.org/10.3122/jabfm.2012.03.100183

Saunders, P. (1989). The meaning of "home" in contemporary english culture. Housing Studies, 4(3), 177-192. http://doi.org/10.1080/02673038908720658

Seo, Y. K. (2010). The meaning of home to Korean immigrant elderly: Growing old in Lilac Villa. University of California, Irvine. Retrieved from http://pqdtopen.proquest.com/doc/527777013.html?FMT=ABS\&pubnum=3404702

Shaw, M. (2004). Housing and public health. Annual Review of Public Health, 25, 397-418. 
http://doi.org/10.1146/annurev.publhealth.25.101802.123036

Shenk, D., Kuwahara, K., \& Zablotsky, D. (2004). Older women's attachments to their home and possessions. Journal of Aging Studies, 18(2), 157-169. http://doi.org/10.1016/j.jaging.2004.01.006

Sixsmith, J. (1986). The meaning of home: an exploratory study of environmental experience. Journal of Environmental Psychology, 6(4), 281-298. http://doi.org/doi:10.1016/S0272$\underline{4944(86) 80002-0}$

Soilemezi, D., Drahota, A., Crossland, J., \& Stores, R. (2017). The role of the home environment in dementia care and support: Systematic review of qualitative research. Dementia, O(0), 1-36. http://doi.org/10.1177/1471301217692130

Somerville, P. (1992). Homelessness and the meaning of home: rooflessness or rootlessness. International Journal of Urban and Regional Research, 16(4), 529-539. http://doi.org/10.1111/j.1468-2427.1992.tb00194.x

Swenson, M. M. (2010). The meaning of home to five elderly women. Health Care for Women International, 19(5), 381-393. http://doi.org/10.1080/073993398246160

Tamm, M. (1999). What does a home mean and when does it cease to be a home? Home as a setting for rehabilitation and care. Disability and Rehabilitation, 21(2), 49-55. http://doi.org/10.1080/096382899297963

Tanner, B., Tilse, C., \& de Jonge, D. (2008). Restoring and sustaining home: The impact of home modifications on the meaning of home for older people. Journal of Housing For the Elderly, 22(3), 195-215. http://doi.org/10.1080/02763890802232048

Taşc1, S., Kartın, P. T., Ceyhan, Ö., Sungur, G., \& Göriş, S. (2012). Living with an Alzheimer patient in Turkey. Journal of Neuroscience Nursing, 44(4), 228-234. http://doi.org/10.1097/JNN.0b013e3182527627.

Teeland, L. (1998). Home, sick: Implications of health care delivery in the home. 
Scandinavian Housing and Planning Research, 15(4), 271-282.

http://doi.org/10.1080/02815739808730462

Van Cauwenberg, J., Van Holle, V., Simons, D., Deridder, R., Clarys, P., Goubert, L., ...

Deforche, B. (2012). Environmental factors influencing older adults' walking for transportation: a study using walk-along interviews. The International Journal of

Behavioral Nutrition and Physical Activity, 9(1), 85. http://doi.org/10.1186/1479-5868$9-85$

van Hoof, J., \& Kort, H. S. M. (2009). Supportive living environments: a first concept of a dwelling designed for older adults with dementia. Dementia, 8(2), 293-316. http://doi.org/10.1177/1471301209103276

Vasunilashorn, S., Steinman, B. a, Liebig, P. S., \& Pynoos, J. (2012). Aging in place: evolution of a research topic whose time has come. Journal of Aging Research, 2012, 120952. http://doi.org/10.1155/2012/120952

Wiles, J. L., Leibing, A., Guberman, N., Reeve, J., \& Allen, R. E. S. (2011). The meaning of "ageing in place" to older people. The Gerontologist, 52(3), 357-366. http://doi.org/10.1093/geront/gnr098

World Health Organisation. (2012). Dementia: a public health priority. Geneva.

Zingmark, K., Norberg, A., \& Sandman, P. (1995). The experience of being at home throughout the lifespan. Investigation of persons aged from 2 to 102. International Journal of Aging \& Human Development, 41(1), 47-62. Retrieved from: https://www.ncbi.nlm.nih.gov/pubmed/8530193 